Louisiana State University

LSU Digital Commons

Faculty Publications

Department of Biological Sciences

$10-15-2019$

\title{
Environmentally persistent free radicals: Linking air pollution and poor respiratory health?
}

\author{
Peter D. Sly \\ The University of Queensland \\ Stephania A. Cormier \\ The University of Queensland \\ Slawomir Lomnicki \\ Louisiana State University \\ Jeffrey N. Harding \\ Louisiana State University \\ Keith Grimwood
}

See next page for additional authors

Follow this and additional works at: https://digitalcommons.Isu.edu/biosci_pubs

\section{Recommended Citation}

Sly, P., Cormier, S., Lomnicki, S., Harding, J., Grimwood, K., \& University, G. (2019). Environmentally persistent free radicals: Linking air pollution and poor respiratory health?. American Journal of Respiratory and Critical Care Medicine, 200 (8), 1062-1063. https://doi.org/10.1164/rccm.201903-0675LE

This Letter to the Editor is brought to you for free and open access by the Department of Biological Sciences at LSU Digital Commons. It has been accepted for inclusion in Faculty Publications by an authorized administrator of LSU Digital Commons. For more information, please contact ir@lsu.edu. 


\section{Authors}

Peter D. Sly, Stephania A. Cormier, Slawomir Lomnicki, Jeffrey N. Harding, Keith Grimwood, and Griffith University 


\section{Environmentally Persistent Free Radicals: Linking Air Pollution and Poor Respiratory Health?}

\section{To the Editor:}

Epidemiological links between exposure to air pollution (both indoor and outdoor) and adverse respiratory outcomes are strong $(1,2)$, but the mechanism(s) involved remains obscure. Although oxidative stress (OS) is presumed to be involved, a direct culprit is lacking. We propose that a recently recognized by-product of thermal and combustion processes that is capable of inducing OS is the missing link between exposure and respiratory disease. These products are called environmentally persistent free radicals (EPFRs).

The term "environmentally persistent free radical" sounds like an oxymoron. Free radicals are generally short lived, rapidly reacting with other molecules or each other (nanoseconds to seconds). However, EPFRs persist in both the environment and biological systems for prolonged periods. We have measured EPFRs in particulate matter $\leqslant 2.5 \mu \mathrm{m}$ in aerodynamic diameter in Baton Rouge with a half-life of 21 days (3). An increasing number of studies are demonstrating the presence of EPFRs in a variety of environmental settings, including traffic-related air pollution (TRAP), coal dust, and other combustion residues. EPFRs are generated in the cool zone of combustion systems when an organic pollutant forms stable bonds with a metal in a reduced state (4), resulting in the formation of a stable EPFR (Figure 1). The reaction rate increases with temperature (low rate at room temperature, fast rate at $180-300^{\circ} \mathrm{C}$ as found in combustion exhausts). EPFRs form readily in the cool-zone regions of combustion systems and other thermal processes. EPFRs can include semiquinones, phenoxyls, and cyclopentadienyls formed by the thermal decomposition of molecular precursors such as catechols, hydroquinones, and phenols. EFPRs are measured by electron paramagnetic resonance (i.e., electron spin resonance), with a variable known as the g-factor, which describes the distribution of the electron spin, indicating the oxidative potential of the EPFR and $\Delta \mathrm{H}$ (peak to peak), which describes the width of the resonance peak that reflects the distribution of core atoms (oxygen or carbon). EPFRs participate in the redox cycle in biological systems through the Fenton reaction and produce reactive oxygen species, with long-lasting effects in biological systems (5). We have shown that EPFRs induce OS in animal models (6) and in human cells (7)-effects that can be mitigated with antioxidants such as resveratrol.

We measured EPFRs in house dust collected from the homes of children from a community-based, longitudinal birth cohort that was established to investigate the patterns of acquisition of common respiratory viruses and bacteria in the upper airway (8). As part of a 4-year assessment, dust samples were collected from the home vacuum cleaners, brought to the clinic, frozen at $-20^{\circ} \mathrm{C}$, and subsequently shipped to Louisiana State University for EPFR analysis. Parents kept a daily symptom diary and collected weekly nasal swabs for the first 2 years of the child's life. Children were seen in the clinic close to their third and fourth birthdays for clinical and respiratory assessments. Wheeze history was extracted to 4 years of age.

Ninety house dust samples, obtained from the houses of 74 children, were analyzed and EPFRs were detected in all but one of them. The EPFR levels varied, with 36 classed as low $\left(<4 \times 10^{17}\right.$ spins/g), 35 classed as moderate $\left(4-6 \times 10^{17}\right.$ spins/g), and 19 classed as high $\left(\geqslant 6 \times 10^{17}\right.$ spins/g). The group mean of the $g$-factor was $2.0036(\mathrm{SD}=0.00023)$ and the group mean $\Delta \mathrm{H}$ was $6.27(\mathrm{SD}=0.62)$. Among the children with dust samples, 42 (56.7\%) reported wheeze ever, 10 (13.5\%) reported transient wheeze, 43 (58.3\%) reported persistent wheeze, and $39(52.7 \%)$ reported current wheeze at the time of the dust sampling. We used machine learning algorithms (CORElearn), stratified random sampling methods, and the random forest algorithm to predict persistent wheeze outcome from the EPFR data (9). When a household provided more than one dust sample, only the first one analyzed was used in these analyses. We put the random forest model through a 10 -fold cross-validation using 500 trees each before calculating the prediction error rate in the model. The continuous EPFR variables weight, $\mathrm{g}$-factor, $\Delta \mathrm{H}$ peak to peak, and concentration were used together with categorical outcome variables of family history of atopy, environmental tobacco smoke exposure, eczema, wheeze ever, persistent wheeze, and transient wheeze. The random forest model was able to predict 55\% (sensitivity $15.4 \%$, specificity $92.8 \%$ ) of the outcome of persistent wheeze correctly using a combination of the g-factor, $\Delta \mathrm{H}$ peak to peak, and concentration of EPFRs.

These preliminary data raise some intriguing possibilities. EPFRs result from inefficient combustion processes, with TRAP

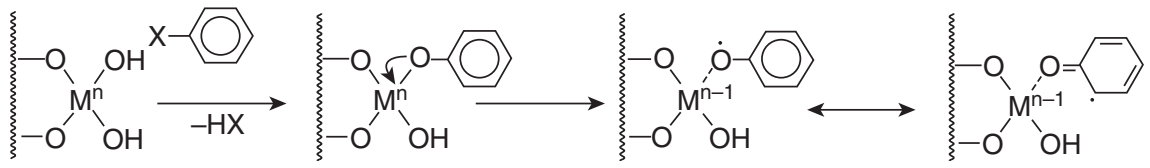

Physisorption followed by Chemisorption

Electron transfer

Stable EPFR

Figure 1. Environmentally persistent free radicals (EPFRs) are generated in the cool zone of combustion systems when an organic pollutant forms initially a van der Waals-type bond with a metal (M) on the surface of a particle (represented by squiggly lines) in a process called physisorption. This is followed by water or hydrogen halide $(\mathrm{HX})$ release to form a chemical bond with the metal, known as chemisorption. The organic pollutant reduces the metal by donating an electron, resulting in the formation of a stable EPFR.

Originally Published in Press as DOI: 10.1164/rccm.201903-0675LE on June 25, 2019 believed to be a major source in ambient air. Penetration of TRAP into homes is variable, but it may be substantial depending on factors such as air conditioning, open windows, and not removing shoes on entering (10). Alternatively, combustion sources inside the 
home, such as gas cooking or heating and cigarettes or e-cigarettes, can produce EPFRs and may be more important in the indoor environment. The presence of EPFRs in settled dust inside the home demonstrates their longevity in the environment but likely represents an underestimate of the child's exposure. The association between EPFR characteristics and wheeze status argues in favor of the involvement of OS. If further investigation confirms this to be the case, boosting antioxidant defenses may help protect children from the adverse effects of air pollution. There are several limitations in our data. We do not have estimates of TRAP or indoor particulate exposure for our cohort, and it is possible that the association between wheeze status and EPFRs is due to some other component of air pollution. Finally, our cohort is small, and thus our study did not have the power to examine the effects of EPFRs on lung growth. However, we contend that our data are intriguing and warrant further studies to address the deficiencies in our preliminary data.

\section{Author disclosures are available with the text of this letter at} www.atsjournals.org.

Peter D. Sly, M.D., D.Sc. ${ }^{\star \ddagger}$

University of Queensland

Brisbane, Australia

Stephania A. Cormier, Ph.D. University of Queensland

Brisbane, Australia

and

Louisiana State University

Baton Rouge, Louisiana

Slawomir Lomnicki, Ph.D. Jeffrey N. Harding, Ph.D.

Louisiana State University

Baton Rouge, Louisiana

Keith Grimwood, M.D.

Griffith University

Gold Coast, Australia

ORCID ID: 0000-0002-6050-6172 (S.A.C.).

${ }^{*}$ P.D.S. is Associate Editor of AJRCCM. His participation complies with American Thoracic Society requirements for recusal from review and decisions for authored works.

‡Corresponding author (e-mail: p.sly@uq.edu.au).

\section{References}

1. Goldizen FC, Sly PD, Knibbs LD. Respiratory effects of air pollution on children. Pediatr Pulmonol 2016;51:94-108.

2. Saravia J, Lee GI, Lomnicki S, Dellinger B, Cormier SA. Particulate matter containing environmentally persistent free radicals and adverse infant respiratory health effects: a review. J Biochem Mol Toxicol 2013;27:56-68.

3. Gehling W, Dellinger B. Environmentally persistent free radicals and their lifetimes in PM2.5. Environ Sci Technol 2013;47:8172-8178.

4. Dellinger B, Lomnicki S, Khachatryan L, Maskos Z, Hall RW, Adounkpe $\mathrm{J}$, et al. Formation and stabilization of persistent free radicals. Proc Combust Inst 2007;31:521-528.

5. Gehling W, Khachatryan L, Dellinger B. Hydroxyl radical generation from environmentally persistent free radicals (EPFRs) in PM2.5. Environ Sci Technol 2014;48:4266-4272.

6. Lee GI, Saravia J, You D, Shrestha B, Jaligama S, Hebert VY, et al. Exposure to combustion generated environmentally persistent free radicals enhances severity of influenza virus infection. Part Fibre Toxicol 2014;11:57.
7. Balakrishna S, Lomnicki S, McAvey KM, Cole RB, Dellinger B, Cormier SA. Environmentally persistent free radicals amplify ultrafine particle mediated cellular oxidative stress and cytotoxicity. Part Fibre Toxicol 2009;6:11.

8. Lambert SB, Ware RS, Cook AL, Maguire FA, Whiley DM, Bialasiewicz S, et al.; Observational Research in Childhood Infectious Diseases. Observational Research in Childhood Infectious Diseases (ORChID): a dynamic birth cohort study. BMJ Open 2012;2:e002134.

9. Elfil M, Negida A. Sampling methods in clinical research; an educational review. Emergency (Tehran) 2017;5:e52.

10. Sbihi H, Brook JR, Allen RW, Curran JH, Dell S, Mandhane P, et al. A new exposure metric for traffic-related air pollution? An analysis of determinants of hopanes in settled indoor house dust. Environ Health 2013;12:48.

Copyright (C 2019 by the American Thoracic Society

\section{Detection of Expiratory Flow Limitation by Forced Oscillations during Noninvasive Ventilation}

In patients with chronic obstructive pulmonary disease (COPD) receiving noninvasive ventilation (NIV), an external positive endexpiratory pressure (PEEP) is used to counteract the intrinsic PEEP (PEEPi) (1). PEEPi increases work of breathing (2) and is associated with tidal expiratory flow limitation (EFLT) (3). PEEP should be set at the minimum level required to abolish PEEPi: insufficient PEEP will not counteract the PEEPi, whereas excessive PEEP may worsen pulmonary hyperinflation, affect hemodynamics $(4,5)$, and cause unnecessary patient discomfort. The possibility of assessing the presence of EFLT at the bedside during NIV may provide useful information for tailoring PEEP to individual patients.

The difference between inspiratory and expiratory respiratory reactance $(\Delta \mathrm{Xrs})$ measured by the forced oscillation technique (FOT) at $5 \mathrm{~Hz}$ noninvasively detects EFLT breath by breath during spontaneous breathing and nasal continuous positive airway pressure (6-8).

The aim of this study was to validate sensitivity and specificity of $\Delta \mathrm{Xrs}$ for the identification of flow-limited breaths in patients with COPD receiving bilevel positive pressure support when different inspiratory and expiratory pressures are applied and the rapid transition between the two may affect the accuracy. Some of the results of these studies have been previously reported in the form of an abstract (9).

\section{Methods}

The study was approved by the South Sefton District Ethics Committee; written informed consent was obtained from all patients. Patients were prospectively enrolled at the Aintree University Hospital between July and August 2010. Inclusion criteria: stable

This study was partially supported by Philips Respironics.

Author Contributions: Conception and design: R.R., P.M.A.C., and R.L.D. Data acquisition: B.C., L.G., and R.R. Data analysis: E.Z., L.G., and P.P.P. First draft of the manuscript: E.Z. Critical revision of the manuscript: P.P.P., P.M.A.C., and R.L.D. Approval of the final version of the manuscript: all authors.

Originally Published in Press as DOI: 10.1164/rccm.201903-0570LE on June 26, 2019 